\title{
Research Paper \\ Developing Germophobia Questionnaire: A Pilot Study on Psychometric Characteristics
}

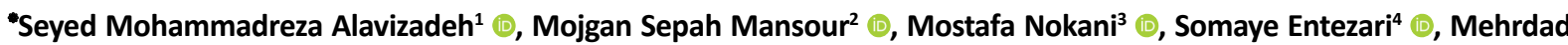

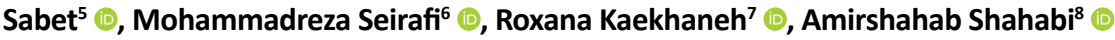

\author{
1. Department of Psychology, Electronic Branch, Islamic Azad University, Tehran, Iran. \\ 2. Department of Psychology, Central Tehran Branch, Islamic Azad University, Tehran, Iran. \\ 3. Department of Psychiatry, School of Medicine, Arak University of Medical Science, Arak, Iran. \\ 4. Department of Psychology, Electronic Branch, Islamic Azad University, Tehran, Iran. \\ 5. Department of Psychology, Roudehen Branch, Islamic Azad University, Roudehen, Iran \\ 6. Department of Psychology, Karaj Branch, Islamic Azad University, Karaj, Iran. \\ 7. Department of Psychology, Science and Research Branch, Islamic Azad University, Tehran, Iran. \\ 8. Department of Computer Engineering, South Tehran Branch, Islamic Azad University, Tehran, Iran.
}

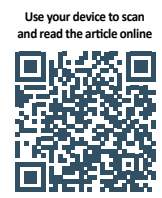

Citation: Alavizadeh SM, Sepah Mansour M, Nokani M, Entezari S, Sabet M, Seirafi M, et al. [Developing Germophobia Questionnaire: A Pilot Study on Psychometric Characteristics (Persian)]. Journal of Arak University of Medical Sciences (JAMS). 2021; 24(4):496-511. https://doi.org/10.32598/JAMS.24.4.1587.2

d०i'https://doi.org/10.32598/JAMS.24.4.1587.2

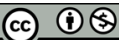

Article Info:

Received: 25 Dec 2020

Accepted: 29 may 2021

Available Online: 01 Oct 2021

Keywords:

Psychometric

Properties, Validity,

Reliability, Germo-

phobia, Germopho-

bia Questionnaire,

COVID-19

\section{A BST RACT}

Background and Aim The World Health Organization has recently identified COVID-19 as a pandemic. The outbreak of the disease has caused many people around the world to become extremely frightened and they show phobic signs. The purpose of the present study was to develop and normalize of Germophobia Questionnaire (GPQ).

Methods \& Materials The participants were 113 individuals (74-female) of the Iranian population. They completed the GPQ and Y-BOCS.

Ethical Considerations All ethical principles and privacy policies of the results informed the participants. This study was approved in the second session of the Psychological Committee of the Islamic Azad University of Tehran's province in March 2020.

Results The results illustrate that the GPQ has acceptable internal consistency with Cronbach's alpha coefficient $(a=0.67)$, reliability coefficients with split-half $(0.72)$, and one-week test-retest $(\mathrm{r}=0.73)$; in addition, the GPQ demonstrate moderate convergent validity with contamination obsessions checklist of Y-BOCS ( $r=0.44)$ as a convergent coefficient; and finally, the exploratory factor analysis indicates three-factors of the GPQ. Conclusion Based on these findings, the GPQ has acceptable and good psychometric properties; researchers can use the GPQ as a reliable and valid instrument for assessing the germophobia levels in epidemic and pandemic crises like COVID-19.

\section{Extended Abstract}

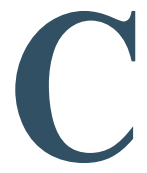

\section{Introduction}

oronavirus Disease 2019 (COVID-19) has recently been epidemic spread world- wide. The "affected areas" based on reports of the World Health Organization (WHO) are considered those countries, provinces, territories, or cities experiencing ongoing transmission of COVID-19, in contrast to areas reporting only imported cases. As of 27 February 2020, although China, especially the province of Hubei, has experi-

\section{* Corresponding Author:}

Seyyed Mohammadreza Alavizadeh, PhD.

Address: Department of Psychology, Electronic Branch, Islamic Azad University, Tehran, Iran.

Tel: +98 (912) 3667765

E-mail: alavizadehsmr@gmail.com 
Table1. English, 3 factors of GPQ and their loadings

\begin{tabular}{|c|c|c|c|}
\hline \multirow[b]{2}{*}{ Items } & \multicolumn{3}{|c|}{ Component } \\
\hline & $\begin{array}{l}\text { Worry (Negative } \\
\text { Meta-Beliefs) } \\
\text { About Germs }\end{array}$ & $\begin{array}{c}\text { Avoidance } \\
\text { From Suspi- } \\
\text { cious Situations }\end{array}$ & $\begin{array}{c}\text { Positive } \\
\text { Meta-Beliefs } \\
\text { About Germs }\end{array}$ \\
\hline 10. I am always worried that viruses and bacteria infect my family and me. & 0.703 & & \\
\hline $\begin{array}{l}\text { 6. The fear of being infected by viruses and bacteria is more important than being } \\
\text { exposed to them. }\end{array}$ & 0.688 & & \\
\hline 9. By hearing the news about viruses and bacteria, the fear of them levels up in me. & 0.591 & & \\
\hline 7. I become aggressive with whoever sneezes or coughs in public. & 0.505 & & \\
\hline 2. I should reduce my worries about viruses and bacteria. & 0.402 & & \\
\hline $\begin{array}{l}\text { 5. It is necessary to prevent contact with healthcare practitioners dealing with } \\
\text { contagious diseases. }\end{array}$ & & 0.687 & \\
\hline 4. I cannot tolerate animals because I am scared they might make me ill seriously. & & 0.681 & \\
\hline 8. To avoid germs, I do not eat food that is not homemade by a relative or me. & & 0.670 & \\
\hline $\begin{array}{l}\text { 3. The use of alcohol, iodine, cleaners, and antibacterial personal-care products } \\
\text { makes me feel more comfortable. }\end{array}$ & & & 0.728 \\
\hline $\begin{array}{l}\text { 1. The feeling of "frightened" of Coronavirus family such as SARS, MERS, and } \\
\text { COVID-19 would result in me living longer. }\end{array}$ & 0.39 & & 0.672 \\
\hline
\end{tabular}

enced sustained local transmission, they reported many confirmed cases since the outbreak. Lately, the situation in China has shown a significant decrease in cases. Concurrently, an increasing number of countries, rather than China, have reported cases, including through local transmission of COVID-19 [1]. Stressful life events are with subsequent psychosocial problems [2]; in a meta-analysis, researchers report a total of 27,475 subjects included in 12 studies. The results indicated that the incidence of anxiety equaled $25 \%$ (95\% CI: $0.19-0.32)$, and the incidence of depression was measured as $28 \%$ (95\%CI: $0.17-0.38)$. In a cross-sectional study among Iranian students, mild to severe anxiety and depression prevalence was $38.1 \%$ and $27.6 \%$, respectively. Anxiety and changes in sleep patterns were the most common symptoms. High anxiety levels were related to the female gender, lower Grade Point Average (GPA), and experience of COVID-19 symptoms; students with lower GPA and prior experiences of COVID-19 symptoms were more likely to feel depressed [3].

Sometimes, germophobia is mysophobia, microphobia, bacteriophobia, bacillophobia, verminophobia, and germaphobia. It is distress about microorganisms, such as bacteria, viruses, germs, and pollution. Phobias are exaggerated, irrational, persistent, and excessive fear about situations and objects. The specific phobia belongs to anxiety disorders in the 5th edition of the Diagnostic And Statistical Manual of mental disorders (DSM-5). The fear or anxiety associated with the presence of a particular situation or object that can be recognized as the phobic stimulus is a crucial key feature of this disorder [4]. Germophobia is an irrational fear of germs [5]. Rituals characterize it as repeated behavior for control and the obsession with contamination $[6,7]$. Moreover, it could be a psychological issue among individuals [8].

These facts led the researchers to investigate the phobias of the virus and bacteria in the Iranian adult population. The researchers developed a questionnaire for assessing germophobia, according to the fact that there is no available standard instrument.

\section{Materials \& Methods}

The study sample was 113 individuals of the Iranian population. They believed they were concerned about germs. They were selected with snowball sampling and completed study questionnaires based on the Internet. The 83 participants completed the Germophobia Questionnaire (GPQ) and the Yale-Brown Obsessive-Compulsive Scale (Y-BOCS) after a week as a retest assessment. 


\section{Results}

The results illustrate that the GPQ has minimum acceptable internal consistency with Cronbach's alpha coefficient $(\mathrm{a}=0.67)$. The reliability coefficients with split-half were $(0.72)$, and one-week test-retest (0.73). Furthermore, the GPQ demonstrates moderate convergent validity with the contamination obsessions checklist of Y-BOCS $(\mathrm{r}=0.44)$. Finally, the exploratory factor analysis indicates 3-factors of the GPQ (see Table 1 English). The results also illustrate no differences between the levels of germophobia among men and women, different demographic statuses.

\section{Discussion \& Conclusion}

Based on the obtained findings, the GPQ has acceptable and good psychometric properties; thus, researchers can use the GPQ as a reliable and validated instrument for assessing the germophobia levels in epidemic and pandemic crises, like COVID-19.

The results indicate no gender-wise differences between germophobia levels different demographic statuses. These findings were also reported by [34-36] but are opposed to [37]. Distel et al. (2008) examined the genetic and environmental influences in a large sample of Dutch twins on specific phobias. Accordingly, they assessed their interaction with gender and age. There were no significant differences among genders in the influence of genetic effects. Besides, there was no evidence for genotype $x$ sex interactions [34]. As mentioned earlier, COVID-19 has become a pandemic. People are exposed to a common virus and fail to find a vaccine. It has caused a general fear of the disease [36]; in such circumstances that everyone is bombarded by real or fake news from different sources, the anxiety level will be definitively increased; as a result of most individuals, regardless of their gender, educational degree, marital status, and also those with and without a history of the infectious disease may have some quasi-germophobic experiences.

This study has some limitations. The first limitation of this study was that the samples were selected from the general population with relatively high education then they were not assessed by interviews or self-report. Another limitation of the present study was that the research was conducted due to the COVID-19 pandemic, which can be considered history-graded influences [38]; this may increase participants' scores in GPQ. In future research, this questionnaire should also be studied in other populations such as persons with generalized anxiety disorder, obsessive-compulsive disorder, patients with infectious diseases, other significant developmental periods, and lower educational status. Eventually, it is recommended that the study of these proposed populations be repeated in the subsequent periods when the COVID-19 pandemic is over.

\section{Informed consent}

Informed consent was obtained from all individual participants included in the study.

\section{Ethical Considerations}

\section{Compliance with ethical guidelines}

All procedures performed in the present study involving human participants were per the ethical standards of the institutional and national research committee (the study was approved by the Department of Psychology and Research Program Committee (RPC) of COVID-19 in Tehran Provincial branches of IAU), PCO of IRI, and with the 1964 Helsinki declaration and its later amendments or comparable ethical standards. This article also does not contain any studies with animals performed by any authors.

\section{Funding}

Any organization or institution did not fund this study; it was performed by personal budget.

\section{Authors' contributions}

This study did not have any financial support from governmental, non-governmental, academic or non-academic institutions and organizations.

\section{Conflicts of interest}

All authors declared no conflicts of interest. 


\title{
ساخت يرسش نامه هراس از ميكروب: مطالعه مقدماتى ويثزَّى هاى روانسنجي
}

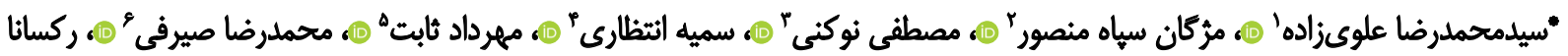

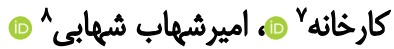

\author{
ا. ا.كروه روانشناسى، واحد الكثرونيك، دانشكاه آزاد اسلامى، تهران، ايران.

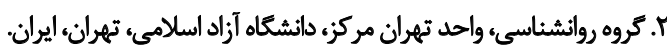

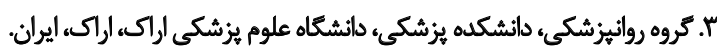

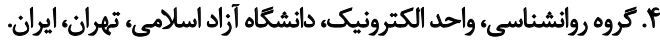

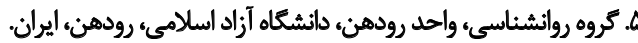

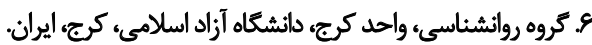

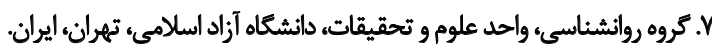

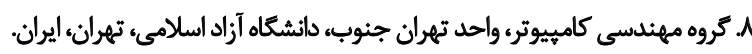

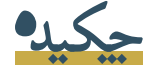

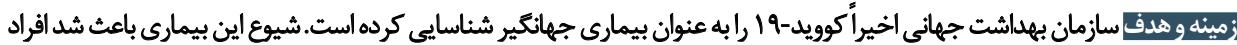

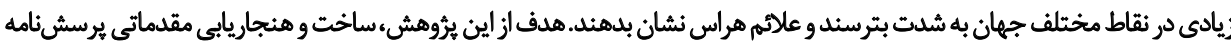
هراس از ميكروب در جمعيت ايران بوده است.

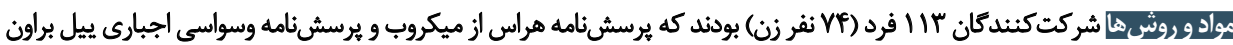

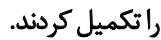

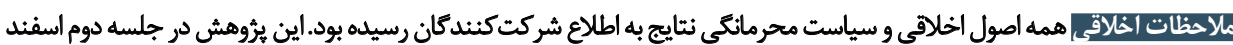

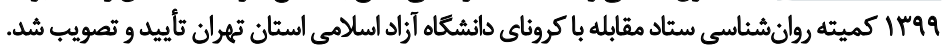

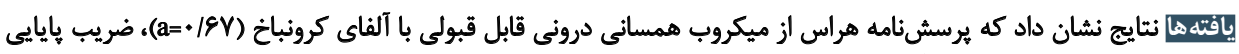

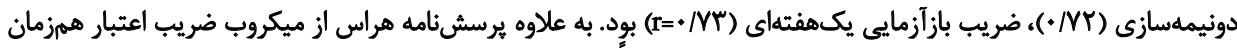

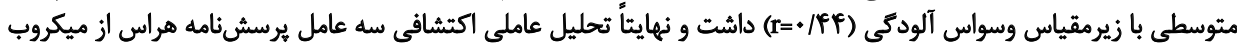

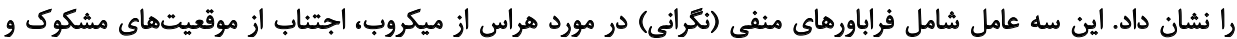

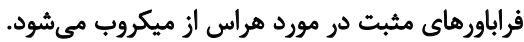

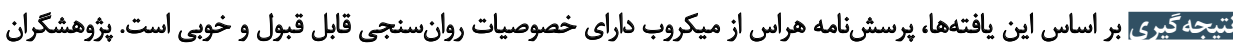

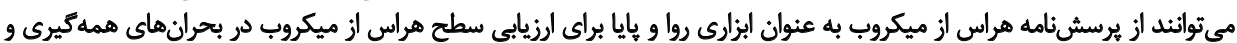
جهائكيرى مائند كوويد-19 الستفاده كنيند.
|طلاعات مقاله:

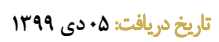

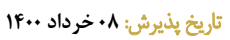

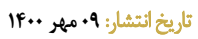

كليدوأوهان: حُصوصيات روان سينجي، اعتبار، روايي، هرواس روني

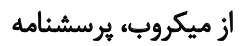

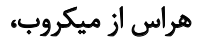
كوويد-19

مى كنند، برخلاف مناطقى كه فقط موارد وارداتى را گزارش

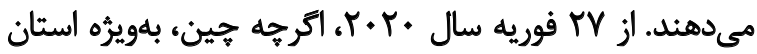

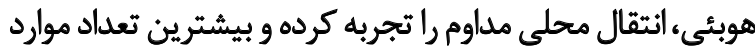

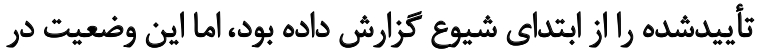

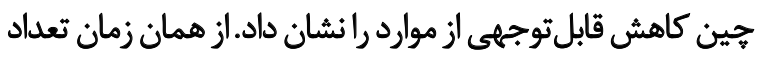

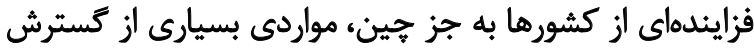

بيمارى كرونا ويروس 19 • ب (كوويد-9 1) كه اخيراً در سراسر

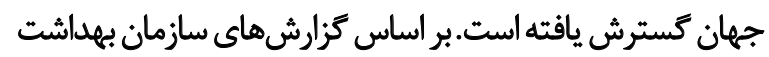

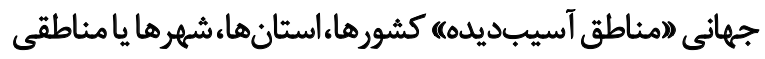

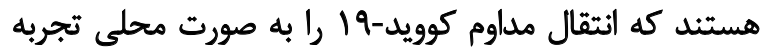


"إياكسازى) ميكروبها از بلن فردو اشياى اطراف ديده مي شود.

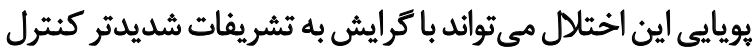

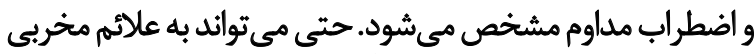

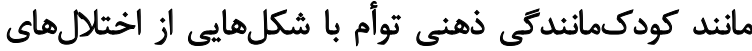

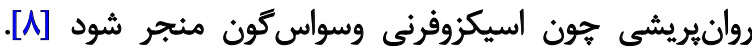

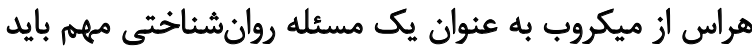

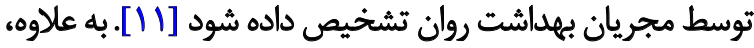

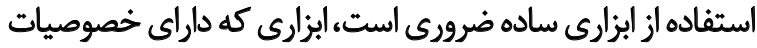

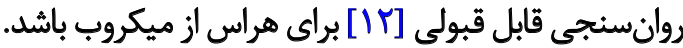

اين حقايق، يُوهشكُران را بر آن داشت تا هراس از ويروس و

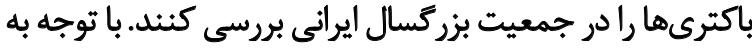

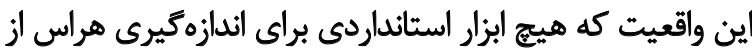

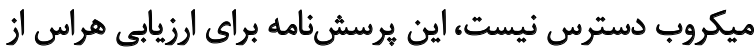

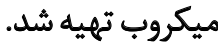
مواد و روشى نها

اين يروهش از نوع يروهشهاي توصيفى تحليلى است كه به

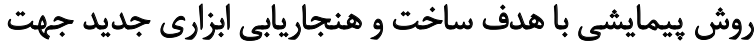

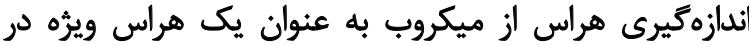

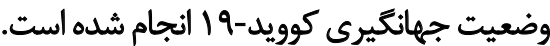

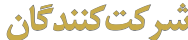

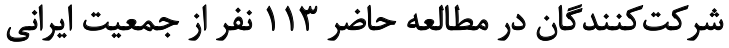

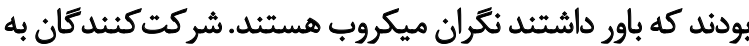

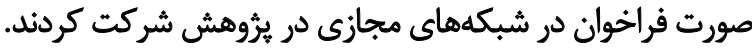

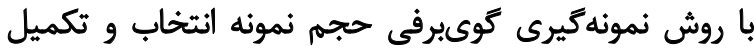

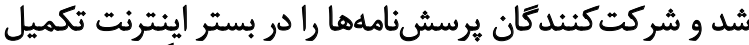

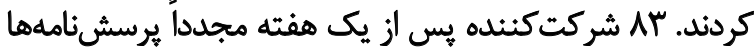

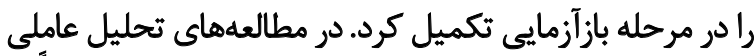

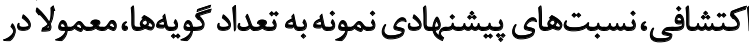
محدوده ده ثا بيست نفر براى هر متغير اندازهيري نيرى است.

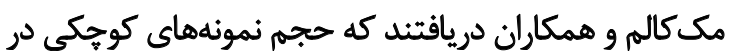

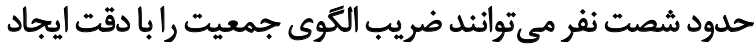

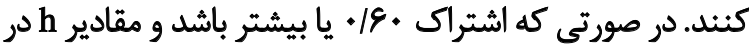

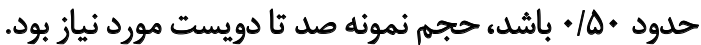

أبوزئ)

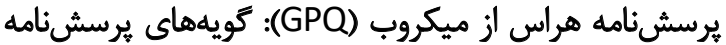

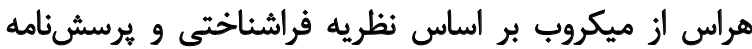

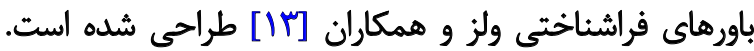

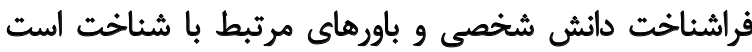

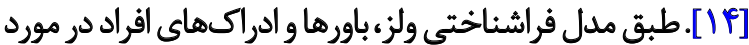
فرايندهاى شناختى شان نقش مهمى در بروز و ايجاد اختلال هائى
ويروس با انتقال محلى كوويد-19 راكَّارش كردند [1]. به دليل روابط اقتصادى، فرهنتَى و سياسى با جين، ايران به

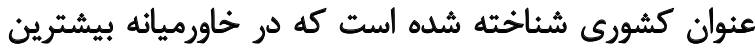

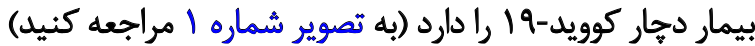

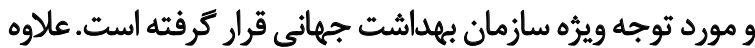

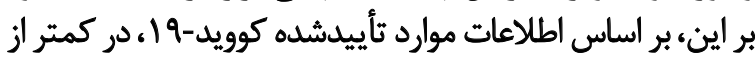

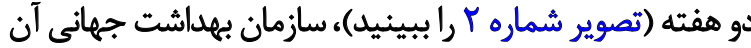

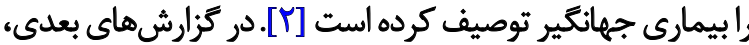

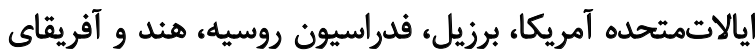

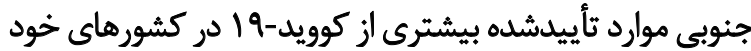

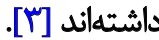

با توجه به جهانكيرى كوويد-19 ا، ترس از بيمارى و مركى در

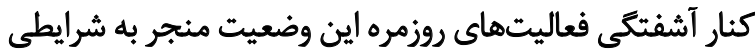

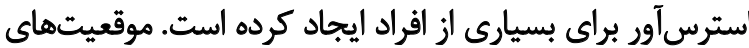

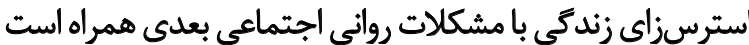

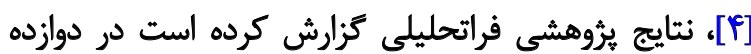

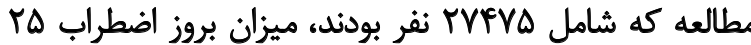

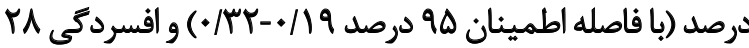

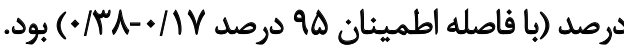

در يك مطالعه مقطعى بين دانشجويان ايرانى شيوع اضطراب

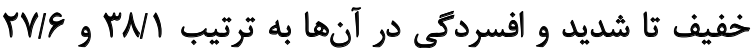

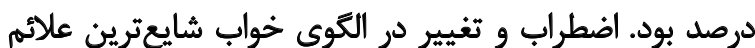

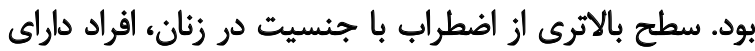

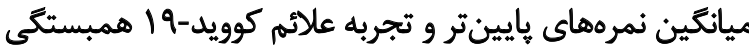

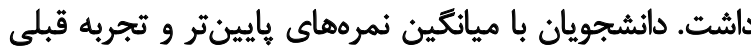

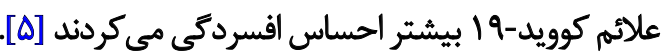
هراس از ميكروب كه گاهى به عنوان آلودتىهراسى،

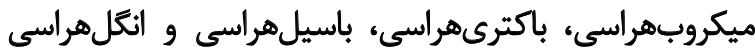

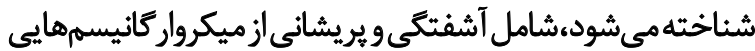

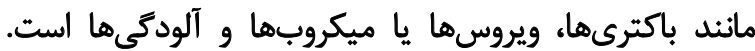

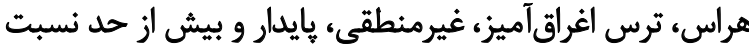

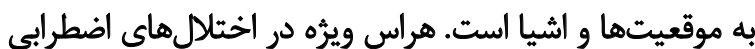

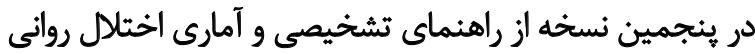
(D-DSM)

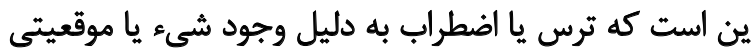

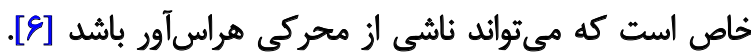

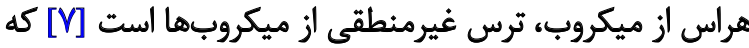

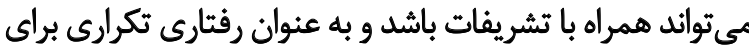

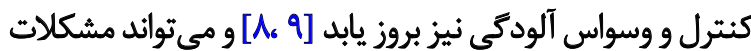

روانشناختى شديدى در ميان افراد ايجاد كند [ـ [1].

هراس از ميكروب با كنترل مكرر و ترس ناشى از آلودتى

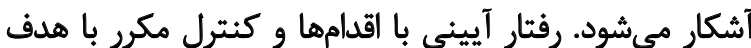




\section{Distribution of COVID-19 cases as of 12 March 2020}

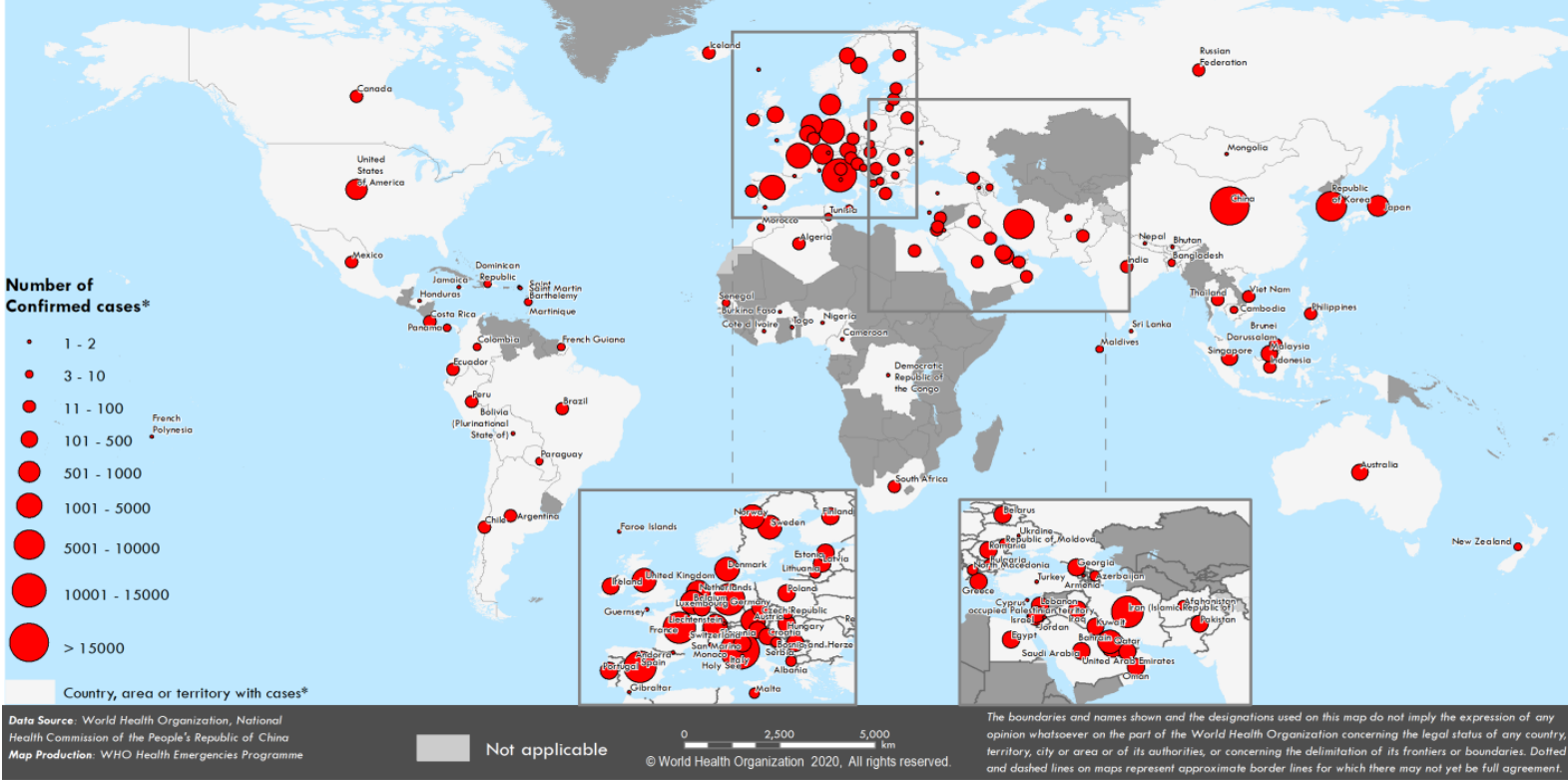

فراشناختى منفى در مورد خطر و غيرقابل كنترل بودن نكرانى

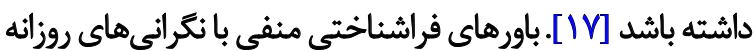

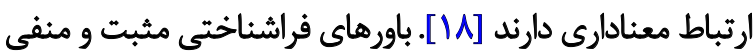

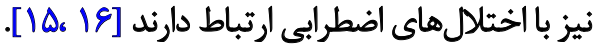

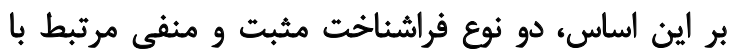

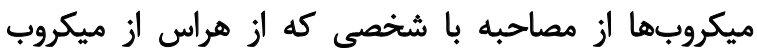

اضطرابى و نكَرانى بيماركونه بازى مى كند [10].

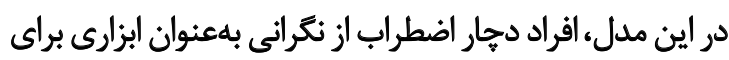

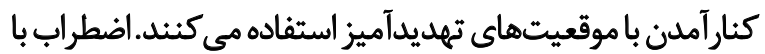

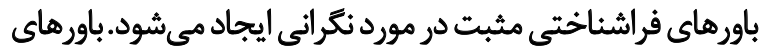

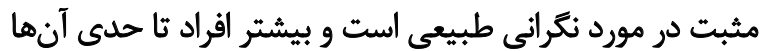

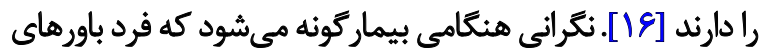

\section{Distribution of COVID-19 cases as of 01 March 2020}

World Health

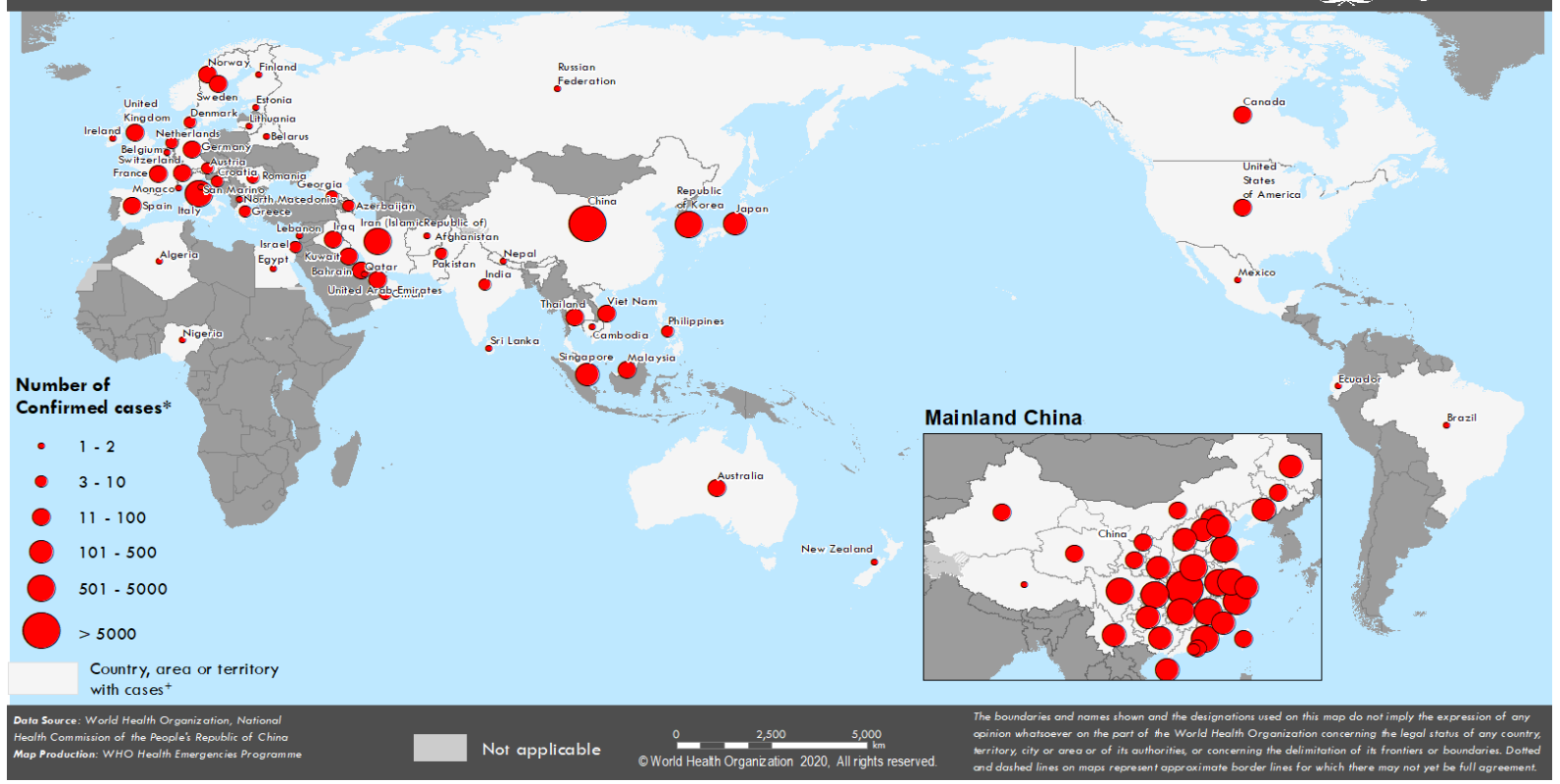


جدول ا. يافتههاي جمعيتشناختى و مقايسه خردهمقياس هاى هراس از ميكروب

\begin{tabular}{|c|c|c|c|c|c|c|}
\hline $\mathbf{P}$ & درجه آزادى & $t / f$ & درصد تجمعى & تعداد (درصد) & زيرمقياس & مقياس \\
\hline \multirow{3}{*}{.$/ 7 q$} & \multirow{3}{*}{111} & \multirow{3}{*}{$V \cdot r$} & 80 & $v_{f}(\varphi \Delta)$ & زن & \multirow{3}{*}{ جنسيت } \\
\hline & & & & & & \\
\hline & & & $1 .$. & $r q(r \Delta)$ & مرد & \\
\hline \multirow{5}{*}{.190} & \multirow{5}{*}{$1+1, f$} & \multirow{5}{*}{.180} & $1 m / \pi$ & $1 \otimes(I \Psi / N)$ & دييلم & \multirow{5}{*}{ تحصيلات } \\
\hline & & & $r V / f$ & $18(1+/ 1)$ & فوقدييلم & \\
\hline & & & va/s & $\Delta q(\Delta T / T)$ & كارشناسيى & \\
\hline & & & $9 \% / \wedge$ & $18(1 \% / r)$ & 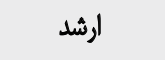 & \\
\hline & & & $1 .$. & $V(\& / M)$ & دكترى و بالاتر & \\
\hline \multirow{8}{*}{.18} & \multirow{8}{*}{$1 \cdot 1, f$} & \multirow{8}{*}{$.18 \lambda$} & $v e / 1$ & $N E(V E /)$ & مجرد & \multirow{5}{*}{ وضعيت تأهل } \\
\hline & & & $9 \vee / r$ & $r F(Y M / T)$ & مثتأهل & \\
\hline & & & awr & $1(\cdot / 9)$ & جلاشده & \\
\hline & & & $99 / 1$ & $1(\cdot / 9)$ & طلاق كرفته & \\
\hline & & & $1 .+$ & $1(\cdot / 9)$ & بيوه & \\
\hline & & & $\Delta / r^{m}$ & $\mathscr{\theta}(\Delta / T)$ & سابقه شخصى & \multirow{3}{*}{ سابقه بيمارى عفونى } \\
\hline & & & $1 T / 6$ & $A(V /)$ & سابقه خاثوادكى & \\
\hline & & & $1 .$. & ११(AV/8) & بلون سابقه & \\
\hline
\end{tabular}

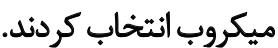
روش تحليل دادهها شامل آمار توصيفى مانند فراوانى، درصد،

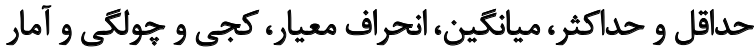

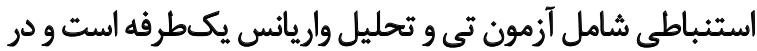

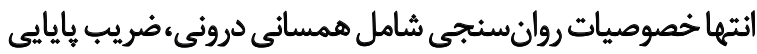

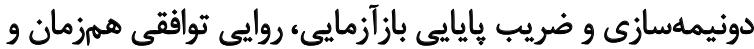

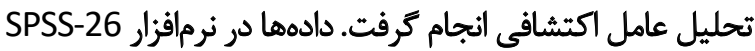
تحليل شد.

يأثتهها

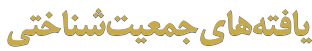

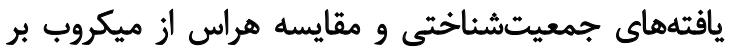

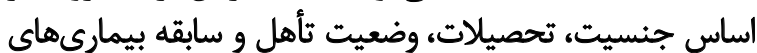
عفونى در جدول شماره إنشان داده شده است.

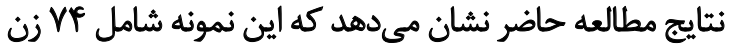

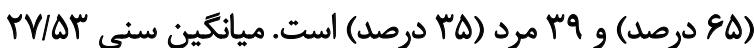

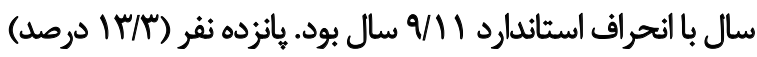

رنج مىبرد، شناسايى شد و در مجموع بنج كويه به هر مؤلفه

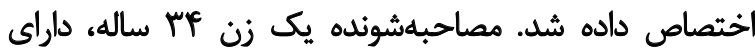

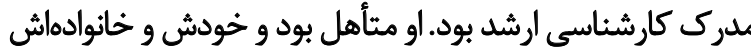

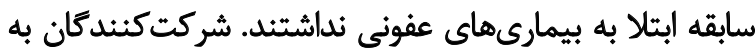

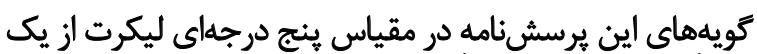

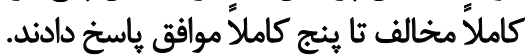

مقياس وسواسى اجبارى ييل براون (Y-BOCS): اين مقياس

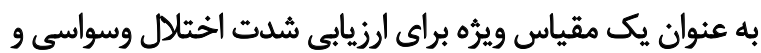

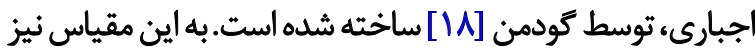

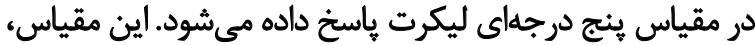

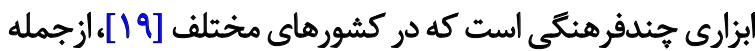

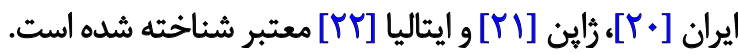
نسخه فارسى اين مقياس داراي سطح بهينه همساني درونى

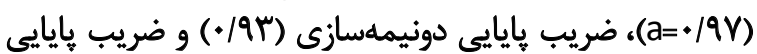

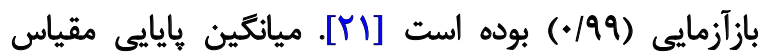

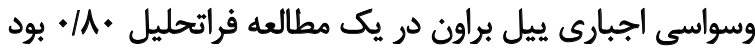

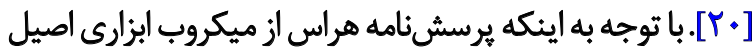

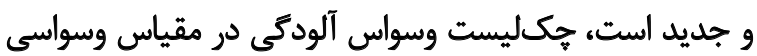
اجبارى ييل براون رابه عنوان ابزارى با ساختار مرتبط با هراس از دري إسي 
جدول r. همبستكى درونى و تحليل تويههاي برسشنامه هراس از ميكروب

\begin{tabular}{|c|c|c|c|c|c|c|c|c|c|c|}
\hline 1. & 9 & $\Lambda$ & $v$ & 8 & $\Delta$ & $f$ & $r$ & $r$ & 1 & كويه \\
\hline.$/ r V$ &.$/ 11$ & r & $\cdot / \pi T$ & .118 & $\bullet / \bullet V$ &.$/ 11$ & . &.$/ 11$ & $1 /$. & 1 \\
\hline.$/ M A$ & .1 .8 &.$/ 11$ &.$/ 1 F$ &. $\mid M^{\prime}$ &.$/ 1 \Delta$ & $.1+\infty$ &.$- / 11$ & $1 / \cdot$ &.$/ 11$ & $r$ \\
\hline.$/ M$ & .1 .8 &.$M T$ &.$/ M$ & $-\cdot / \cdot r$ &.$/ N$ & .10 & $1 /$. & $-\bullet / M$ &.$/ \pi$ & $r$ \\
\hline.$/ K r$ &.$/ \pi 1$ & TH/. &.$/ \pi$ &.$/ N r$ &.$/ \pi$ & $1 / .$. & .1. & $.1 \cdot \Delta$ & .111 & f \\
\hline.$/ r r$ & $\cdot / r r$ &.$/ \pi r$ & r & .109 & $\mathrm{~V} \cdot$ & r & . & $.11 \Delta$ & $\% v$ & $\Delta$ \\
\hline.$/ M$ &.$/ 1 r$ & .1 .9 & $\cdot \pi$ & $1 / .$. & .1 .9 &.$/ 1 r$ & $-.1+r$ & $\cdot|m|$ & .118 & $\varepsilon$ \\
\hline.$/ T V$ & . & r & $1 /$. & $\cdot R$. &.$/ r r$ & . &.$/ r$ &.$/ 14$ &.$/ \pi r$ & $v$ \\
\hline$\cdot / M I$ & . $/ \pi r$ & $1 /$. & . & $.1+9$ & r & r & . &.$/ 11$ & r & $\wedge$ \\
\hline.$/ P V$ & $\mathrm{~V} \cdot \cdot$ & Tr & . / F & . &.$/ r$ & $\cdot / K I$ & $.1 . F$ & 1.9 &.$M 1$ & 9 \\
\hline $1 / .$. &.$/ P V$ &.$/ M$ &.$/ T V$ &.$/ M Y$ &.$/ K r$ &.$/ \pi r$ & . &.$/ 11$ &.$/ T V$ & 1. \\
\hline
\end{tabular}

ميزان تحصيلي (f)

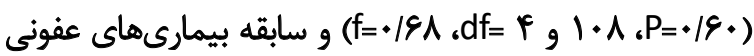

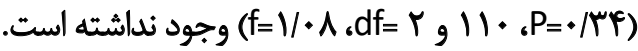

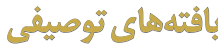

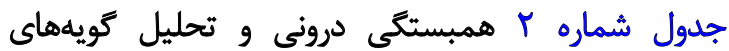

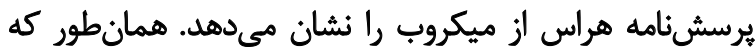

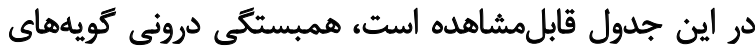

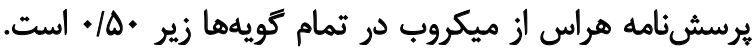

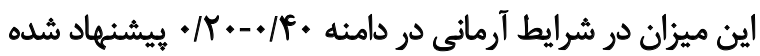

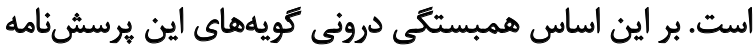

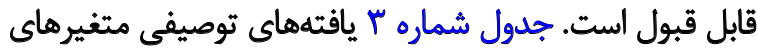

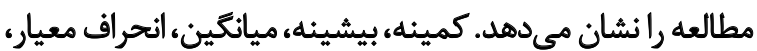

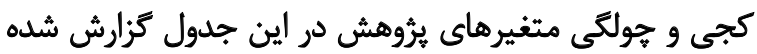

دييلم دبيرستان، شانزده نفر داراي مدرك تحصيلي كارداني

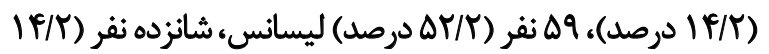

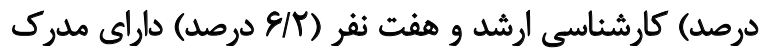
دكترى يا بالاتر بودند.

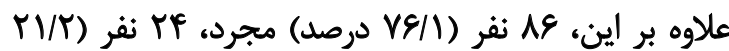

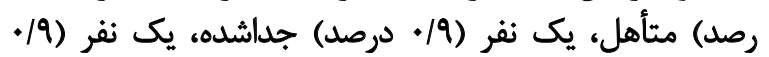

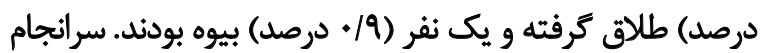

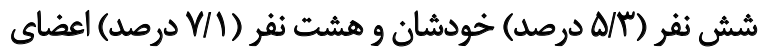

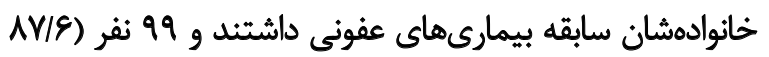
درصد) سابقه بيمارىهاي عفونى نداشتيند.

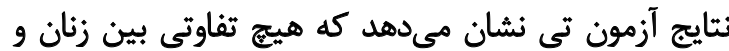

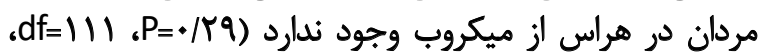

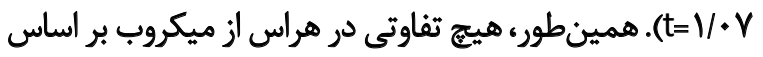

جدول "r. يافتهاي توصيفى متغيرهاى مطالعه

\begin{tabular}{|c|c|c|c|c|c|}
\hline هولِّى & كجى & ميانغين土|نحراف معيار & بيشينه & كمينه & مثير \\
\hline$-* / \cdot r$ & $-\cdot / N$ & $r V / \cdot f \pm \Delta / f r$ & pq & 1. & $\mathrm{GPQ}$ \\
\hline.$/ M T$ & .1 .9 & $\mid r / 1 r \pm r / r q$ & Tr & $\Delta$ & عامل يكمم \\
\hline$-+/ V$ &.$/ M$ & $r / F q \pm . / r$ & if & $r$ & عامل دوم \\
\hline.$- / 191$ &.$/ 19 \Delta$ & $\Delta / A \cdot \pm 1 / \mathscr{F}$ & 1. & r & عامل سوم \\
\hline$-+/ \Lambda$ &.$/ T \Delta$ & $M F / W \pm N D 1$ & fo & 9 & وسواس آلودكى \\
\hline
\end{tabular}


جدول f. نمرات خام، صدكها و نمرات استانداردشده Z

\begin{tabular}{|c|c|c|c|c|c|}
\hline نمره Z & صدى & نمره خام & Z ن Z Z Z & صدى & نمره خام \\
\hline .111 & $e r / A$ & YA & $-r / M f$ & .1 .9 & 1. \\
\hline.$/ 48$ & SNI & rq & $-r / M r$ & $1 / 1$ & 10 \\
\hline .100 & VT/S & r. & $-1 / 1 \Delta$ & $T / N$ & iv \\
\hline$\cdot M$ & $W / q$ & M & $-1 / 8 V$ & $p / f$ & M \\
\hline .191 & $A T / Y$ & r & $-1 / 4 A$ & NA & 19 \\
\hline $1 / 1$ & $N E N$ & rr & $-1 / \pi$ & $11 / \Delta$ & $r$. \\
\hline I/TA & $19 / 4$ & $\mu$ & $-1 / 11$ & $18 /$ & $M$ \\
\hline I/FV & $9 Y / 9$ & ro &.$- / 94$ & $r \cdot / F$ & M \\
\hline $1 / 80$ & $9 \vee / \%$ & re &.$- / V \Delta$ & $\pi / q$ & m \\
\hline I/AF & Wr & $m$ &.$- / \Delta s$ & $r / q$ & rf \\
\hline$r / \cdot r$ & $99 / 1$ & H & $-+/ / \mu$ & rq/A & ro \\
\hline$r / r$. & $99 / 9$ & rq &.$- / 19$ & $F \Delta / 1$ & re \\
\hline$r / r q$ & $1.0 \%$ & p. & $-* 1++1$ & $\Delta E / 8$ & $r V$ \\
\hline
\end{tabular}

خصوصيات ووان سنجيق

بايايى

جدول شماره ه هايايى GPQ رالرائه مي كند. اين جدول نشان

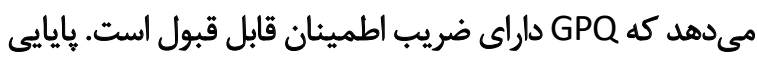

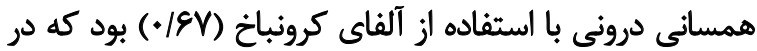

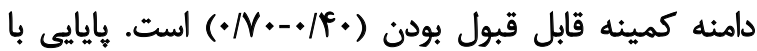

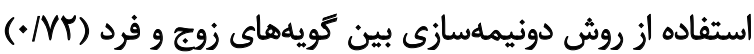

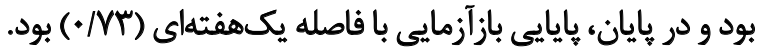

است. دادههاى ستونهاى جولنَى و كجى نشان مى دهد كه تمام

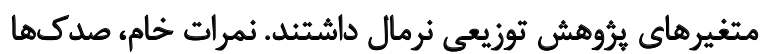

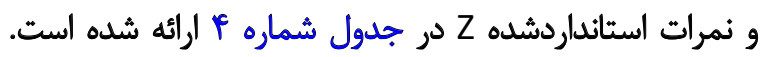

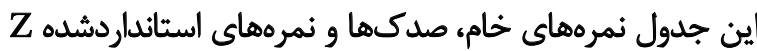

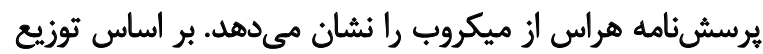

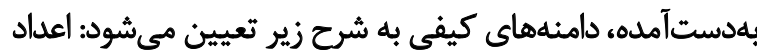

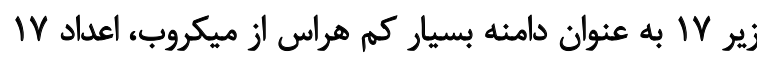

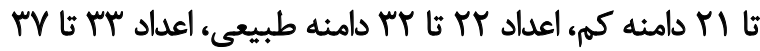

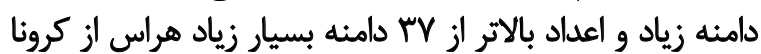
تعيين شدند.

جدول ه. قابليت اطمينان GPQ

\begin{tabular}{|c|c|c|c|}
\hline بازأزمايي (n=AY) & دونيمهسازى & آلفاى كرونباخ & متغير \\
\hline$\cdot M^{n}$ & $\cdot M$ & $.18 V$ & GPQ \\
\hline .188 &.$/ p i$ &.$/ \Delta f^{\circ}$ & عامل يكم \\
\hline$\cdot N$ &.$/ 4 A$ & .101 & عامل دوم \\
\hline$\cdot|A|$ &.$/ 4 A$ &.$/ P A$ & عامل سوم \\
\hline$+/ M$ & - /AF & .119 & وسواس آلودكى \\
\hline
\end{tabular}


جدول \&. ماتريس همبستكى متغيرها

\begin{tabular}{|c|c|c|c|c|c|}
\hline$\Delta$ & $f$ & $r$ & $r$ & 1 & متغير \\
\hline & & & & 1 & GPQ \\
\hline & & & 1 & ./Ar"** & عامل يكم \\
\hline & & 1 & $\cdot / \mathrm{HA*}$ & . NQ** & عامل دوم \\
\hline & 1 &.$/ M E *$ & .110 &.$(\Delta)^{* *}$ & عامل سوم \\
\hline 1 & $+/ M$ & ./Tr** & $+/ 4+*$ & . /peo* & وسواس آللودكى \\
\hline
\end{tabular}

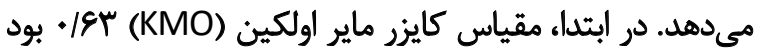

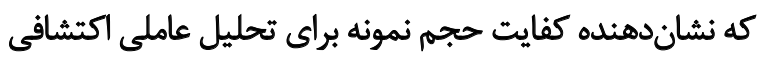

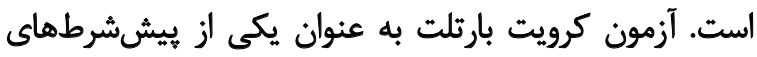

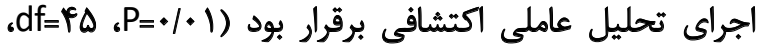
. $X^{2}=19 \% / 94$

ماتريس همبستكى يُيرسون در متغيرها در جدول شماره

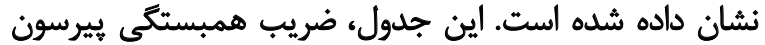
مقادير ويره اوليه در جدول شماره V نشان داده شده است.

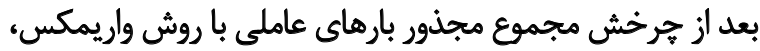

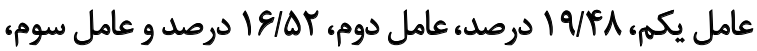

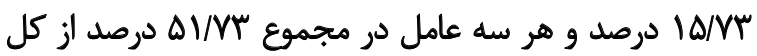

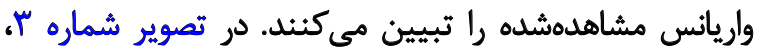

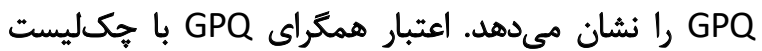

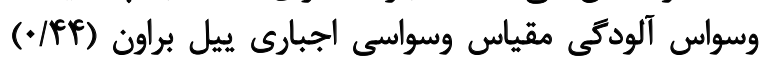

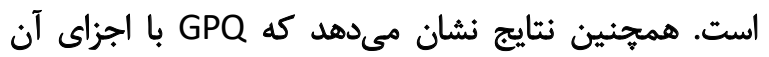

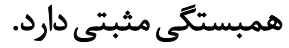

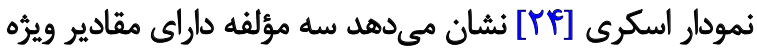
بايائي أعثبار وساؤه

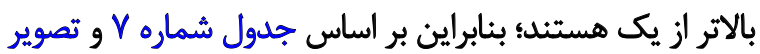

جدول شماره \نتايج تحليل عاملى اكتشافى GPQ را نشان

جدول V. واريانس كل

\begin{tabular}{|c|c|c|c|c|c|c|c|c|c|}
\hline \multicolumn{3}{|c|}{ مجموع مجذور بارهاى يرخيده } & \multicolumn{3}{|c|}{ مجموع مجذور بارهاى استخخراجشده } & \multicolumn{3}{|c|}{ مقادير ويزوه اوليه } & \multirow{2}{*}{ كويه } \\
\hline درصد تجمعى & درصدواريانس تيينى & كل & درصد تجمعى & ترصدواريانس تيينى & كل & درصد تجمعى & درصد واريانس & كل & \\
\hline iqPe & $19 / 2 A$ & $1 / 90$ & rell. & $r e / 1$. & $r(8)$ & rel. & $r e / 1$. & $r / 81$ & 1 \\
\hline rel.. & IE/Or & $1 / 80$ & FI/Ta & $|Q|+\Delta$ & $|/ D|$ & $F Y / 1 Q$ & $|Q|+\Delta$ & $1 / \Delta 1$ & $r$ \\
\hline \multirow[t]{8}{*}{$\Delta 1 / V^{m}$} & $10 / N^{n}$ & $V / \Delta V$ & $\Delta \backslash / M^{\mu}$ & $1+101$ & $1 / \cdot 8$ & $\Delta \backslash M N^{\mu}$ & $1+10 \mathrm{~A}$ & $1 / 48$ & $r$ \\
\hline & & & & & & $81 / 09$ & $q / N C$ &.$/ 99$ & f \\
\hline & & & & & & $V \cdot / A F$ & Q/T৯ & (94 & $\Delta$ \\
\hline & & & & & & VNPE & VIFA & $\cdot M$ & 8 \\
\hline & & & & & & $A \Delta / M I$ & g/AT & $.18 A$ & $\checkmark$ \\
\hline & & & & & & 9.119 & $\Delta / \Delta A$ &.$/ \Delta C$ & $\wedge$ \\
\hline & & & & & & $q(p)$ & $\Delta / \Delta r$ & $\cdot / \Delta \Delta$ & 9 \\
\hline & & & & & & $1 .$. & $r / \Delta q$ & $\cdot / \mu$ & 1. \\
\hline
\end{tabular}




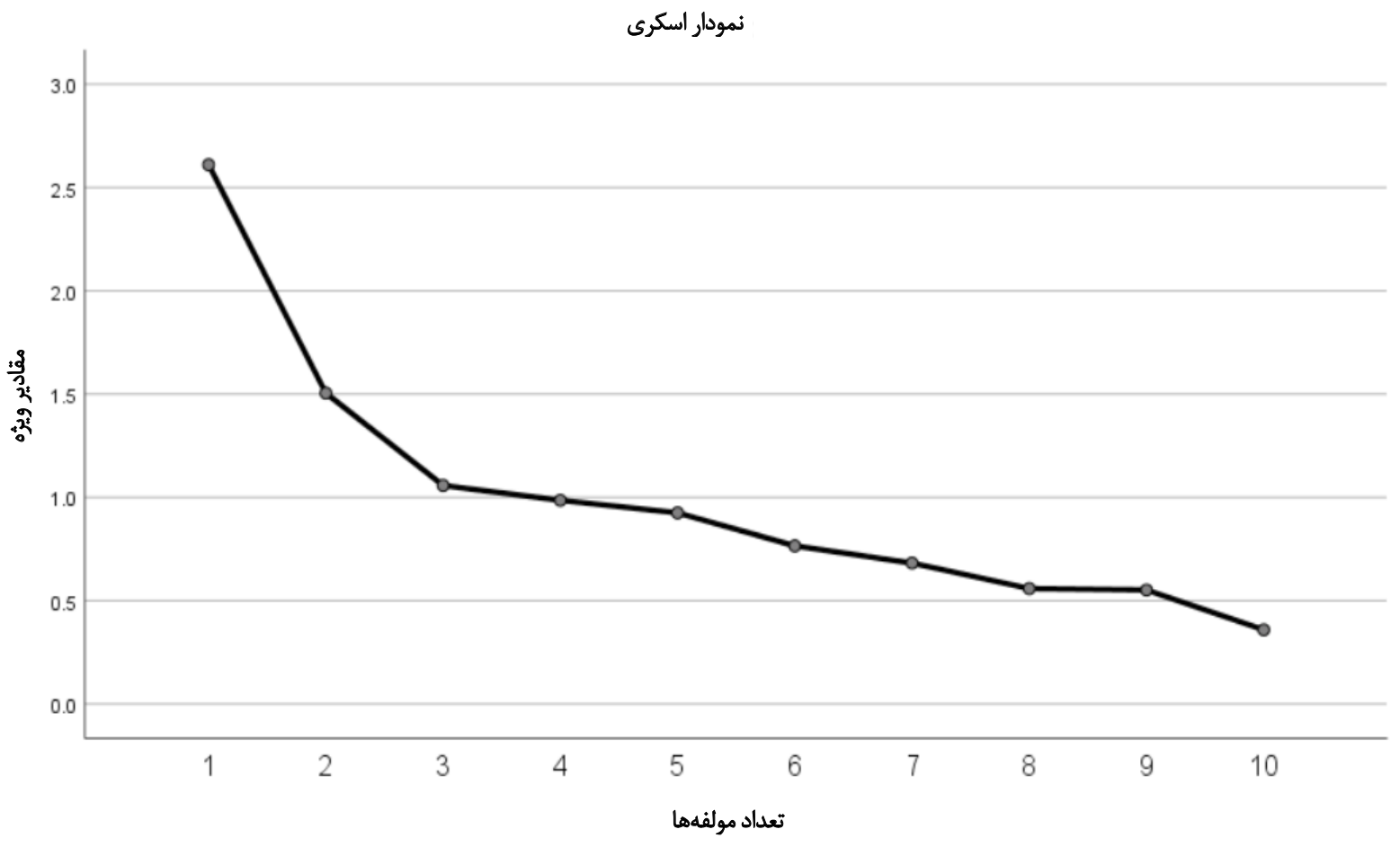

ادراك آلودگى به عنوان محركى كه مي توانثد گَسترش يابد يا

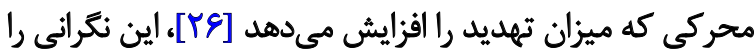

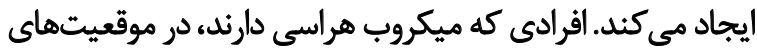

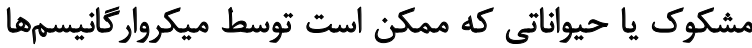

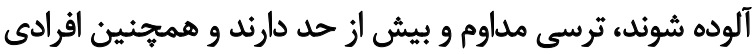

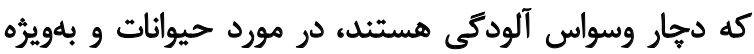

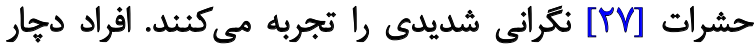

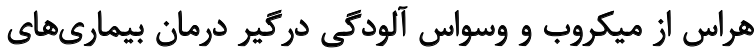

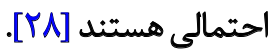

در اين نقطه تفاوتهايى بين افراد دجار هراس از ميكروب و

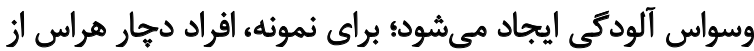

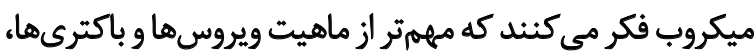

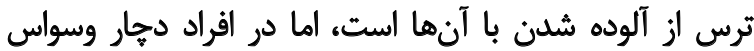

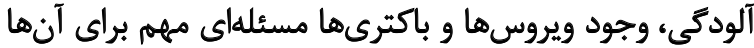

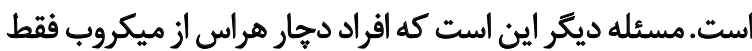

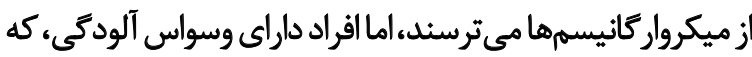

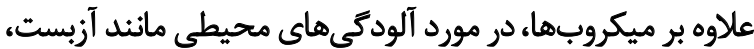

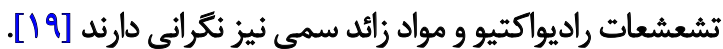
با توجه به جاب ينجم راهنماى تشخيصى و آمارى اختلالهاى

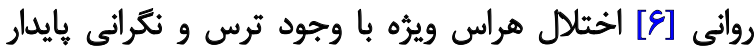

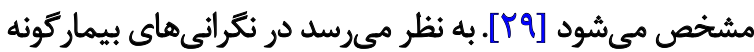

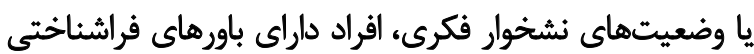
منفى متناقضى در مورد يِيامدهاى احتمالى اين نوع تفكر هستيند
شماره "ז، به عنوان قوانين نكَهدارى عاملها، GPQ داراى سه عامل أست.

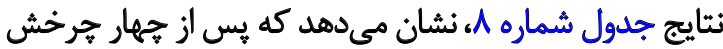

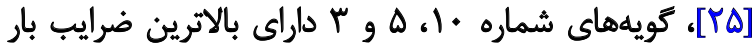

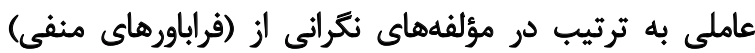

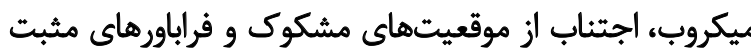
بودند. ضرايب ديكر كويهها بر اساس اندازه مرتب شدهان مراند. مطالعه حاضر يك مطالعه مقدماتى در مورد يرسش نامدامه هراس

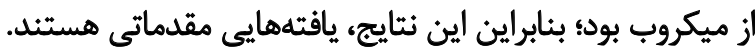

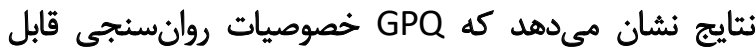

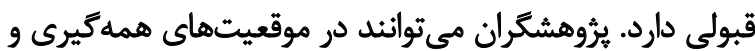

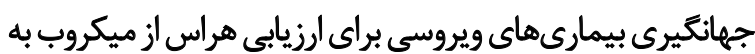
عنوان يك اختلال هراس ويزهاز ائن ابزار استفاده كنيند. با توجه به اين يافتهها، GPQ سه عامل دارد و نويسندكان

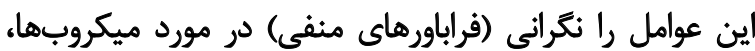

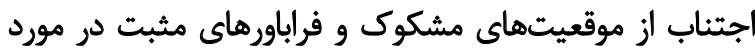

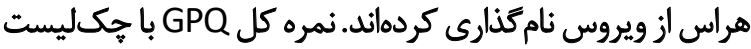

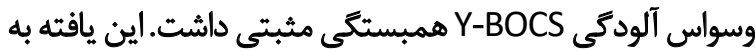

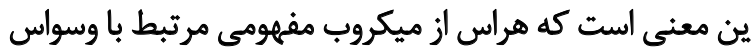

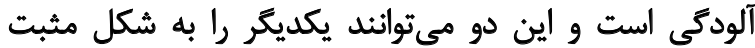

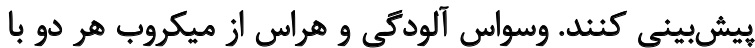

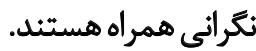


جدول A. نام، مقادير سؤالات و عوامل برسشنامه هراس از كرونا

\begin{tabular}{|c|c|c|c|}
\hline \multicolumn{3}{|c|}{ عاملها } & \multirow[b]{2}{*}{ كويهها } \\
\hline فراباورهاى & الجتناب از موقعيت & نيكرانى از & \\
\hline & & $+/ N$ & •ا. در مورد سلامت خودم و اطرافيانم به ويروس ها و باكترىها هميشه نكران هستم. \\
\hline & & $1 / 99$ & و و مهمتر از خود ويروس ها و باكترى ها، هراس از مبتلا شدن به آنها است. \\
\hline & &.$/ \Delta 9$ & ج. با شنيدن خبرهايع در مورد ويروسها و باكترىها ترس من از آنها بيشتر مىشود. \\
\hline & & $\cdot / \Delta \mid$ & V. آك كسى در مكانهاى عمومى عطسه يا سرفه كند با برخاشكرى با او برخورد مي كثم. \\
\hline & & $\cdot / \varphi$ & r. بايد نكرانيىام رادر هورد ويروس ها و باكترىها كاهش دهم. \\
\hline & .189 & & هـ بايد از تماس با متخصصينى كه با بيمارى ها هسرى كار مى كنثل، اجتناب كرد. \\
\hline & .181 & & F. أز حيوانات دورى مي كنم، زيرا هي ترسم هن را به شدت بيمار كنند. \\
\hline & $.18 \mathrm{~V}$ & & 1 از خوردن غذاهايى كه خودم يا نزديكاثم آنها را ثيختهاند، اجتناب مى كنم تا از ميكروبها دورى مي كنه. \\
\hline$\cdot M$ & & & ". استفاده از تميزكنندهايى مانند الكل، بتادين و ساولون باعث ميشود احساس آرامش بيشترى داشته باشهم. \\
\hline $.19 \mathrm{~V}$ & &.$/ \% 9$ & ا. ترس و هراس در مورد ويروس هايى از قبيل سارس، مرسك و كرونا باعث مى شُود بيشتر زنده بمانم. \\
\hline
\end{tabular}

تصور بر اين است كه فراشناختهاي مثبت نكرائي در مورد وقايع

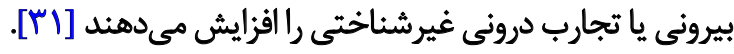
بديهي أست كه سطوح بالاتر باورهاي فراشناختي مثبت در مورد

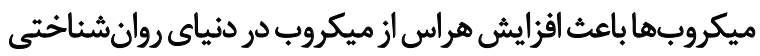

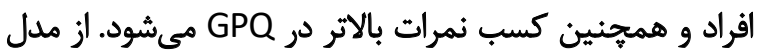

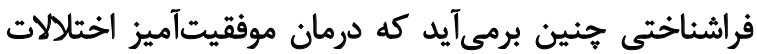

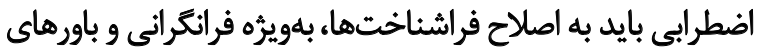

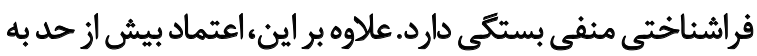

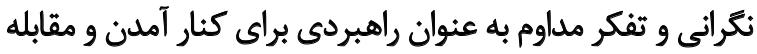

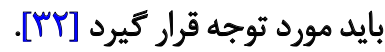

نتايج همجنين نشان هيدهد كه هيت تثاوتي بين هيزان

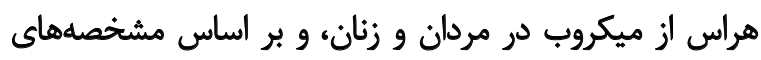

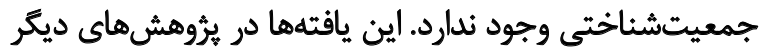

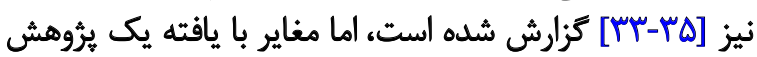

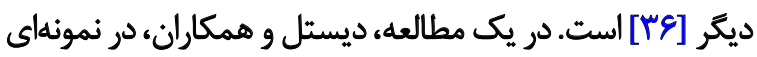

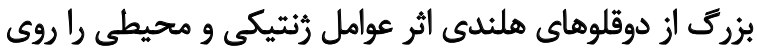

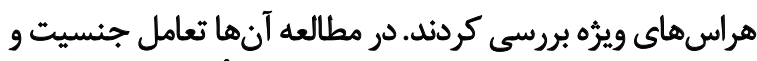

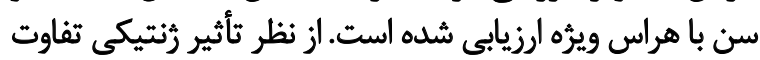

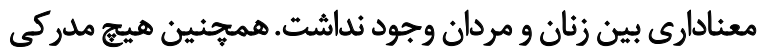

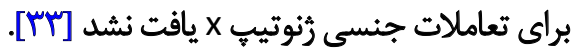

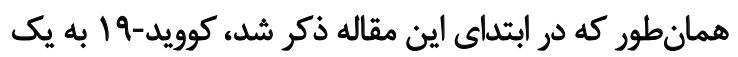

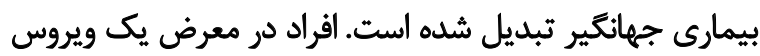

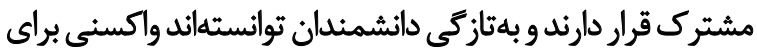

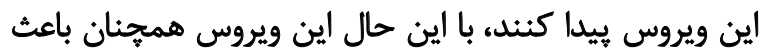

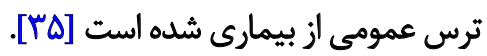

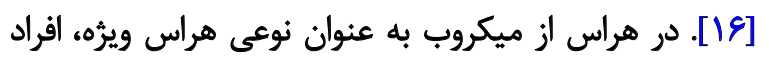

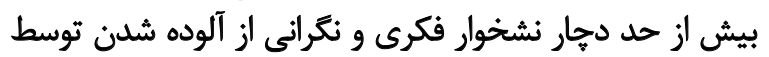

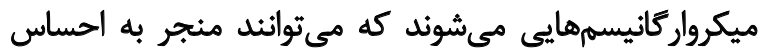
بيمارى شونف.

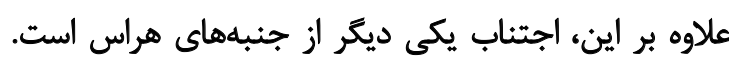

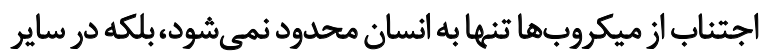

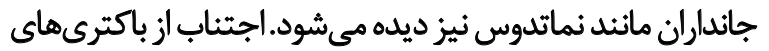

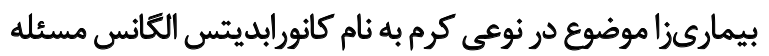

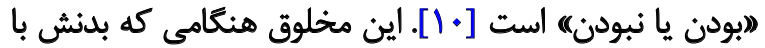

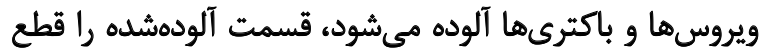

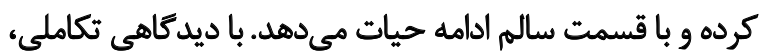

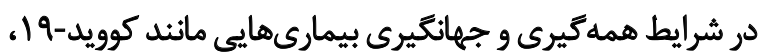

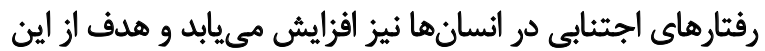

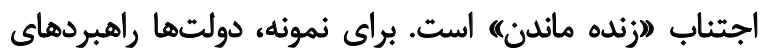
قرنطينهاى و محدوديتهائ آمدوشد رالجن الجرا مى كنيند.

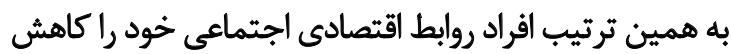

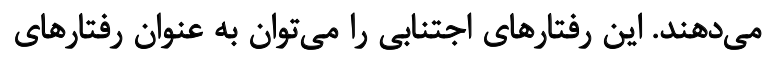

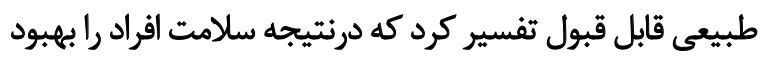

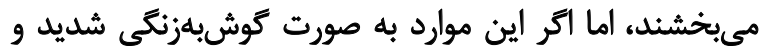

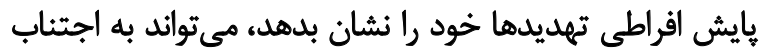

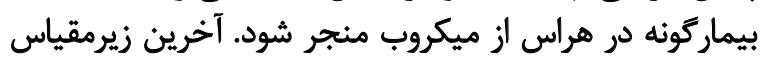

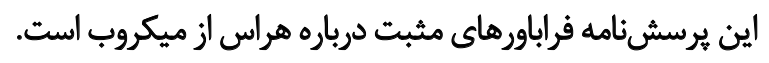
فراباورهاى مثبت به معنادارى و اهميت باورهاى فراشناختى

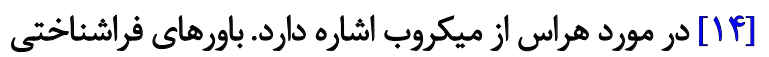

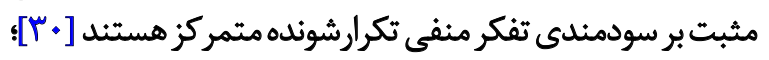


بود). و مطابق استانداردهاي PCO IRI، و با اعلاميه هلسينكى

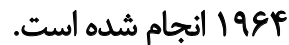

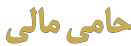

اين مطالعه هيج حامى مالى از نهادها و سازمانهاى دولتى

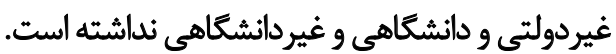

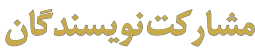

تمام شركت كنند كان در اجراى اين يُؤوش سهيم بودهاند.

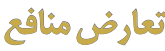

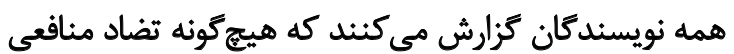

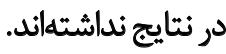

در جنين شرايطى كه همه توسط اخبار جعلى و واقعى از منابع

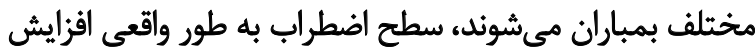

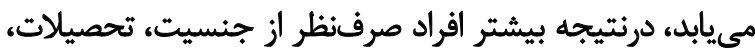

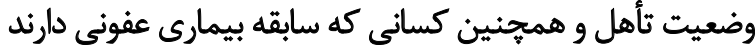

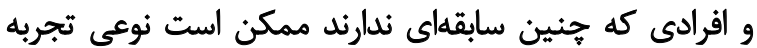

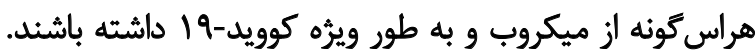

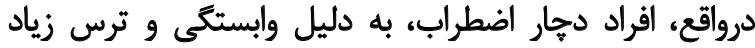

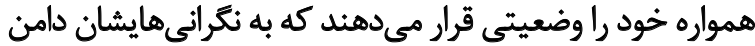

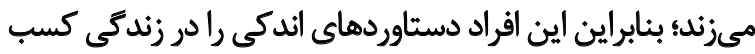

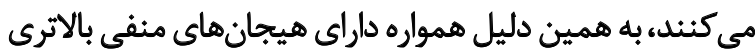

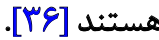

اين مطالعه با محدوديتهايى نيز روبهرو بوده است. اولين

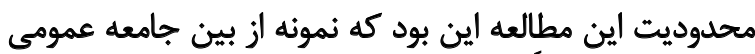

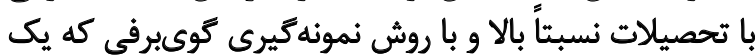

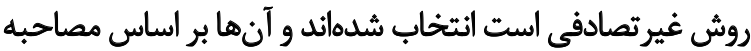
يا ابزار خودَّزارشى ارزيابى نشده بودندا

محدوديت ديكر اين مطالعه اين است كه در دوران شيوع

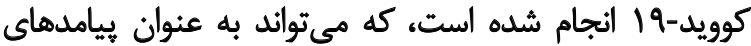

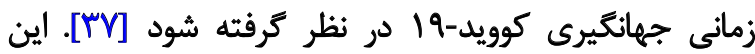

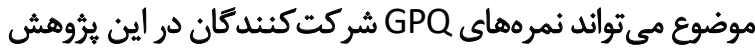

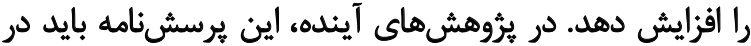

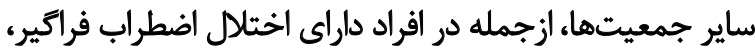

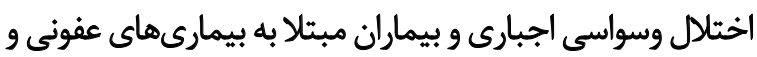

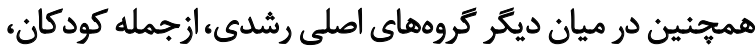

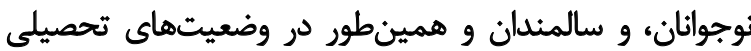

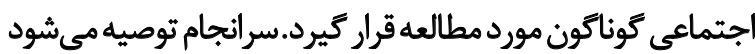

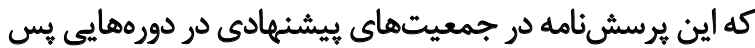
از زايان يافتن جهانتيرى كوويد-19 انكرار شود.

\section{تنيجه تيرى}

بر اساس اين يافتهها، برسشنامه هراس از ميكروب داراى

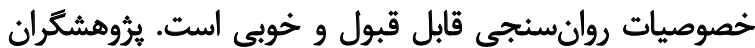

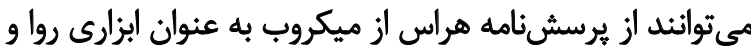

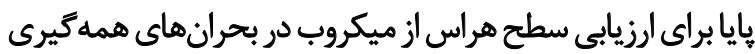
و جهانگيرى مانيد كوويد-19 استفاده كنيند.

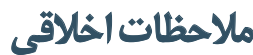

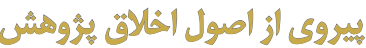

كليه رويههاي انجام شده در يرؤهش حاضر با شركت كنيندكان

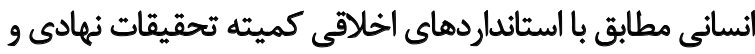

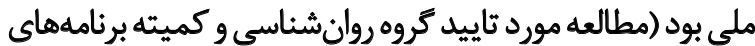

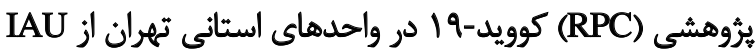




\section{References}

[1] WHO. Coronavirus disease 2019 (COVID-19): Situation report- 41. Geneva: World Health Organization; 2020. https://apps.who.int/iris/ handle/10665/331352

[2] WHO. Coronavirus disease 2019 (COVID-19): Situation report- 52. Geneva: World Health Organization; 2020. https://apps.who.int/iris/ handle/10665/331476

[3] WHO. Coronavirus disease 2019 (COVID-19): Situation report - 172. Geneva: World Health Organization; 2020. https://www.who.int/ docs/default-source/coronaviruse/situation-reports/20200710-covid19-sitrep-172.pdf?sfvrsn=70724b90_2

[4] Mousavi SA-M, Hooshyari Z, Ahmadi A. The most stressful events during the COVID-19 epidemic. Iran J Psychiatry. 2020; 15(3):220-7. [DOI:10.18502/ijps.v15i3.3814] [PMID] [PMCID]

[5] Nakhostin-Ansari A, Sherafati A, Aghajani F, Khonji M, Aghajani $\mathrm{R}$, Shahmansouri N. Depression and Anxiety among Iranian Medical Students during COVID-19 Pandemic. Iran J Psychiatry. 2020; 15(3):228-35. [DOI:10.18502/ijps.v15i3.3815] [PMID] [PMCID]

[6] APA. Diagnostic and statistical manual of mental disorders. 5th ed. Washington DC: American Psychiatric Association; 2013. https:// www.appi.org/diagnostic_and_statistical_manual_of_mental_disorders_dsm-5_fifth_edition

[7] O'Connell EG. Illustrations of child anxiety. Rhode Island: Honors Program at the University of Rhode Island; 2016. https://digitalcommons.uri.edu/cgi/viewcontent.cgi?referer=https://scholar.google.com/ \&httpsredir=1\&article=1508\&context=srhonorsprog

[8] Efremova MD. [Obsessive-phobic disorders with the phenomena of mysophobia in slowly progressing schizophrenia (Russian)]. Zh Nevrol Psikhiatr Im S S Korsakova. 2001; 101(2):12-7. [PMID]

[9] Belova NA. [Inbred disgust propensity in the aspect of the development of pathological personality (Russian)]. Zh Nevrol Psikhiatr Im S S Korsakova. 2012; 112(8):15-20. [PMID]

[10] Lee Y-T, Wang MC. The bacterivore's solution: Fight and flight to promote survival. Dev Cell. 2019; 49(1):7-9. [DOI:10.1016/.j.devcel.2019.03.021] [PMID]

[11] Shojaei SF, Masoumi R. The importance of mental health training for psychologists in COVID-19 outbreak. Middle East J Rehabil Health Stud. 2020; 7(2):e102846. [DOI:10.5812/mejrh.102846]

[12] Zandifar A, Karim H, Qorbani M, Badrfam R. Mental health care for medical staff in iran during the COVID-19 pandemic; Different performance in Alborz province. Iran J Psychiatry. 2020; 15(3):243-7. [DOI:10.18502/ijps.v15i3.3817]

[13] Wells A, Cartwright-Hatton S. A short form of the metacognitions questionnaire: Properties of the MCQ-30. Behav Res Ther. 2004; 42(4):385-96. [DOI:10.1016/50005-7967(03)00147-5]

[14] Wells A. Metacognitive therapy for anxiety and depression. New York: Guilford Press; 2009. https://books.google.com/books?id=sWJgx5-1y4 $A C \&$ printsec=copyright\#v=onepage\&q\&f=false

[15] Bacow TL, May JE, Brody LR, Pincus DB. Are there specific metacognitive processes associated with anxiety disorders in youth? Psychol Res Behav Manag. 2010; 3:81-90. [DOI:10.2147/PRBM.S11785] [PMID] [PMCID]

[16] Wells A, Carter K. Further tests of a cognitive model of generalized anxiety disorder: Metacognitions and worry in GAD, panic dis- order, social phobia, depression, and nonpatients. Behav Ther. 2001; 32(1):85-102. [DOI:10.1016/S0005-7894(01)80045-9]

[17] Smith KE, Hudson JL. Metacognitive beliefs and processes in clinical anxiety in children. J Clin Child Adolesc Psychol. 2013; 42(5):590-602. [DOI:10.1080/15374416.2012.755925] [PMID]

[18] Ramos-Cejudo J, Salguero JM. Negative metacognitive beliefs moderate the influence of perceived stress and anxiety in longterm anxiety. Psychiatry Res. 2017; 250:25-9. [DOI:10.1016/j.psychres.2017.01.056] [PMID]

[19] Goodman WK, Price LH, Rasmussen SA, Mazure C, Fleischmann RL, Hill CL, et al. The yale-brown obsessive compulsive scale. I. development, use, and reliability. Arch Gen Psychiatry. 1989; 46(11):1006-11. [DOI:10.1001/archpsyc.1989.01810110048007] [PMID]

[20] López-Pina JA, Sánchez-Meca J, López-López JA, Marín-Martínez F, Núñez-Núñez RM, Rosa-Alcázar Al, et al. The yale-brown obsessive compulsive scale: A reliability generalization meta-analysis. Assessment. 2015; 22(5):619-28. [DOI:10.1177/1073191114551954] [PMID]

[21] Rajezi Esfahani S, Motaghipour Y, Kamkari K, Zahiredin A, Janbozorgi M. [Reliability and validity of the Persian version of the YaleBrown Obsessive-Compulsive Scale (Y-BOCS) (Persian)]. Iran J Psychiatry Clin Psychol. 2012; 17(4):297-303. http://ijpcp.iums.ac.ir/ article-1-1453-en.html

[22] Ishikawa R, Kobori O, Shimizu E. Development and validation of the Japanese version of the obsessive-compulsive inventory. BMC Res Notes. 2014; 7:306. [DOI:10.1186/1756-0500-7-306] [PMID] [PMCID]

[23] Melli G, Avallone E, Moulding R, Pinto A, Micheli E, Carraresi C. Validation of the Italian version of the Yale-Brown Obsessive Compulsive Scale-Second Edition (Y-BOCS-II) in a clinical sample. Compr Psychiatry. 2015; 60:86-92. [DOI:10.1016/j.comppsych.2015.03.005] [PMID]

[24] Cattell RB. The scree test for the number of factors. Multivariate Behav Res. 1966; 1(2):245-76. [DOI:10.1207/s15327906mbr0102_10] [PMID]

[25] Field A. Discovering statistics using IBM SPSS statistics. 5th ed. London: Sage; 2018. https://books.google.com/books/about/Discovering_Statistics_Using_IBM_SPSS_St.html?id=JIrutAEACAA

[26] Zanjani Z, Yaghubi H, Fata L, Shaiiri M, Gholami M. [The mediating role of fear of contagion in explaining the relationship between disgust propensity and fear of contamination (Persian)]. Iran J Psychiatry Clin Psychol. 2018; 23(4):454-65. [DOI:10.29252/nirp.ijpcp.23.4.454]

[27] Ware J, Jain K, Burgess I, Davey GCL. Disease-avoidance model: Factor analysis of common animal fears. Behav Res Ther. 1994; 32(1):5763. [DOI:10.1016/0005-7967(94)90084-1]

[28] Rouel M, Smith E. Attentional bias and its modification in contamination OCD symptomatology. Cognit Ther Res. 2018; 42(5):686-98 [DOI:10.1007/s10608-018-9927-4]

[29] Davis TE, Ollendick TH, Öst L-G. One-session treatment of specific phobias in children: Recent developments and a systematic review. Annu Rev Clin Psychol. 2019; 15:233-56. [DOI:10.1146/annurevclinpsy-050718-095608] [PMID]

[30] Anderson R, Capobianco L, Fisher P, Reeves D, Heal C, Faija CL, et al. Testing relationships between metacognitive beliefs, anxiety and depression in cardiac and cancer patients: Are they transdiagnostic? J Psychosom Res. 2019; 124:109738. [DOI:10.1016/j.jpsychores.2019.109738] [PMID] 
[31] Sugiura Y. Metacognitive, emotional, and avoidance predictors of generalized anxiety disorder. Psychology. 2017; 8(4):636-53. [DOI:10.4236/psych.2017.84041]

[32] Wells A. Metacognitive theory and therapy for worry and generalized anxiety disorder: Review and status. J Exp Psychopathol. 2010; 1(1):133-45. [DOI:10.5127/jep.007910]

[33] Van Houtem CM, Laine ML, Boomsma DI, Ligthart L, van Wijk AJ, De Jongh A. A review and meta-analysis of the heritability of specific phobia subtypes and corresponding fears. J Anxiety Disord. 2013; 27(4):379-88. [DOI:10.1016/j.janxdis.2013.04.007] [PMID]

[34] Bourdon KH, Boyd JH, Rae DS, Burns BJ, Thompson JW, Locke BZ. Gender differences in phobias: Results of the eca community survey. J Anxiety Disord. 1988; 2(3):227-41. [DOI:10.1016/08876185(88)90004-7]

[35] Mohammadpour M, Ghorbani V, Khoramnia S, Ahmadi SM, Ghvami $M$, Maleki $M$. Anxiety, self-compassion, gender differences and COVID-19: Predicting self-care behaviors and fear of COVID-19 based on anxiety and self-compassion with an emphasis on gender differences. Iran J Psychiatry. 2020; 15(3):213-9. [DOI:10.18502/ijps. v15i3.3813] [PMID] [PMCID]

[36] Fredrikson M, Annas P, Fischer H, Wik G. Gender and age differences in the prevalence of specific fears and phobias. Behav Res Ther. 1996; 34(1):33-9. [DOI:10.1016/0005-7967(95)00048-3]

[37] Fathi A, Sadeghi S, Maleki Rad AA, Rostami H, Abdolmohammadi K. [Effect of health-promoting lifestyle and psychological well-being on anxiety induced by coronavirus disease 2019 in non-medical students (Persian)]. J Arak Univ Med Sci. 2020; 23(5):698-709. [DOI:10.32598/JAMS.23.COV.1889.2]

[38] Berk LE. Development through the lifespan. 7th ed. Boston: Pearson; 2018. https://books.google.com/books/about/Development_ Through_the_Lifespan.html?id=bvXijwEACAAJ 
This Page Intentionally Left Blank 